\title{
College students' knowledge and attitude towards new regulation on smoking ban in public places in Nepal
}

\author{
Sushma Dahal ${ }^{*}$, Sabina Maharjan², Raj Kumar Subedi ${ }^{3}$ Juna Maharjan ${ }^{4}$ \\ ${ }^{1}$ Central Institute of Science and Technology (CIST), Kathmandu, Nepal ${ }^{2}$ Tribhuvan University, Nepal ${ }^{3}$ Central Institute of Science and Technology (CIST), Kath- \\ mandu, Nepal ${ }^{4}$ Lumanti Support Group for Shelter, Nepal
}

\begin{abstract}
Background: Nepal as a signatory to Framework Convention on Tobacco Control (FCTC) in 2003 has passed a new tobacco control bill entitled “Tobacco product control and regulatory bill, 2010" in 2011. On this background, it is imperative to assess the knowledge and attitude of people towards this new regulation that forbids smoking in public places.
\end{abstract}

Methodology: A descriptive cross-sectional study was conducted among 394 students of higher secondary level in three randomly selected colleges of Kathmandu district, Nepal. Information on respondents' awareness on current ban, source of information, implementation status and their attitude towards the new

Received:

11 February 2015

Revised:

09 July 2015

Accepted:

19 July 2015

\section{${ }^{\star}$ Correspondence: sushdahal@gmail.com $\mathrm{MPH}$, Lecturer, Central Institute of Science and Technology (CIST), Sangam Chowk, New Baneshwor, Kathman- du-34, Nepal.} regulation were collected using self-administered questionnaire. Analysis of quantitative data was done using descriptive statistics whereas qualitative data were analyzed manually.

Results: Majority of respondents (79.9\%) said that there is ban on smoking in public places in Nepal. The most common source of information was television (72.3\%), followed by friends (36.5\%) and family members (33.9\%). Most of the respondents (67.4\%) had frequently seen people smoking in public places and $48.8 \%$ had not seen or heard any penalty given to those people. Overall, $74.1 \%$ of the participants stated that the ban on smoking in public places was a 'very good thing. Majority of those who viewed that the ban was good, reasoned 'it will protect people from diseases like cancer'. Those who viewed that the ban was not good, reasoned 'people cannot be changed by compelling' and 'to smoke or not to smoke is people's own will'.

Conclusion: This study shows that majority of adolescents are aware of and have positive attitude towards new regulation on smoking ban in public places in Nepal. There is need of implementing the policy strictly by raising awareness among people and penalizing those who violate it.

Keywords: adolescents, cigarette smoking, regulation, tobacco, Nepal

Suggested citation: Dahal S, Maharjan S, Subedi RK, Maharjan J. College students' knowledge and attitude towards new regulation on smoking ban in public places in Nepal. Health Prospect. 2015;14(2):13-16.

Tweetable abstract: Students support government's effort to ban smoking in public places but say it hasn't been effectively implemented.

\section{Introduction}

Tobacco epidemic is one of the biggest public health threats in the world that kills about six million people a year (1). Both active smoking and passive smoking are important risk factors for many diseases including cardiovascular diseases and cancer (2). Tobacco smoking is associated with ill health, disability and death from non-communicable diseases like cardiovascular diseases, cancer, Chronic Obstructive Pulmonary Disease (COPD) as well as communicable diseases like tuberculosis, lower respiratory tract infection, etc. (3). Smoking in public places causes non-smokers to be exposed to smoking. This act of second hand smoking is associated with increased incidence of cardiovascular diseases, lung cancers and respiratory problems $(4,5)$. Framework Convention on Tobacco Control (FCTC) was one of the important responses of World Health Organization (WHO) to the growing tobacco epidemic that was adopted by World Health Assembly in 2003 and came into force in 2005. FCTC calls for all countries to introduce comprehensive tobacco control policies and strategies as per WHO recommendations (6). Many signatory countries have implemented the smoke free policies so as to decrease the adverse health effects of smoking among smokers and second hand smoking among non-smokers (7-9).

Government of Nepal also implemented the non-smoking policy by signing FCTC in 2003 that was ratified in 2006 (10). In 2011, Nepal approved "Tobacco product control and regulatory bill, 2010" which enforces a complete ban on smoking in public places, workplaces and public transportation. This law discour- 
ages sale of tobacco products to minors and pregnant women and also prohibits such sales by the unlicensed vendors. Similarly, health tax on tobacco products has been introduced and the advertisements, sponsorship and promotion in any forms has been forbidden. Moreover, the law also includes the provision of punishments and penalties to the offenders of the regulation (10). A more recent and stronger legislation (11) that came into force in 2015 requires that all tobacco packaging should strictly cover $90 \%$ of surface area with pictorial health warnings.

Adolescents are one of the key markets of tobacco companies (12). They are the most vulnerable population to initiate tobacco use and most of the adult users of tobacco begin using tobacco products during childhood or adolescence (13). In $\mathrm{Ne}$ pal the prevalence of current cigarette use among those aged 1315 years is $3.1 \%$ (14). Similarly, prevalence of ever smoking was $34.2 \%$ and current smoking was $17 \%$ among youths in Western Nepal (15). Thus, with the new law on tobacco that has come into effect in Nepal, there is need of assessment of knowledge and attitude of adolescents towards it.

A major factor determining the effectiveness of legislation is the level of awareness, concern and support for the legislation that restricts on smoking. The level of awareness and attitude also dictates the level of compliance with the introduced legislation (2). Studies on attitude towards various events and phenomenon are popular among social scientists as they help to predict and understand peoples' behavior (9). Researches carried out in many countries regarding the public opinion on government's efforts to ban smoking in public places have shown strong public endorsement $(2,16)$. However, no such study has yet been documented in Nepal. Thus, assessment of college student's knowledge and attitude towards the governments' ban on smoking in public places will help the government find out the present adherence to the law and start timely the corrective measures to implement the program effectively.

\section{Methods}

A descriptive cross-sectional study was conducted in three randomly selected higher secondary schools of Kathmandu district from March to August 2013. First, a list of 56 colleges in Kathmandu district under Higher Secondary Education Board (HSEB) was obtained and 50 of them gave consent for the study. From this list, 3 colleges were randomly selected for the study. Within these colleges, the students from grade 11 and 12 were randomly included from their attendance sheet using Probability Proportionate to Size (PPS) method. The total sample size of the study was 394 .

Self-administered questionnaire was used to collect data that included both open-ended and close-ended questions. The questionnaire was prepared by using variables from similar studies conducted in other countries $(2,7,9,16)$. Participants' knowledge was measured by using variables like: awareness of current ban, source of information and awareness of penalty for those smoking in public places etc. Attitude was measured by using variables like: view towards current ban, reasons behind their view, and view towards possible preventive measures of smoking in public places etc. The questionnaire was prepared in Nepali language and pretested in a higher secondary school in Bhaktapur district. The questionnaire was translated back to English for analysis and interpretation.

Before administering the questionnaire, informed written consent was obtained from the students. The students thus selected were clearly explained the objectives of study. The questionnaire was administered to the students after a brief orientation. The participants were also asked not to mention their personal identity in the questionnaire. The study was approved by research committee, University Grants Commission (UGC), Nepal.

Data was entered and analyzed using IBM SPSS Statistics 20 for windows PC. Quantitative findings were analyzed using descriptive statistics (measures of central tendency, frequency and percentage) to generate appropriate tables. Qualitative data were analyzed manually by verbatim transcription and content analysis which were presented under different themes.

\section{Results}

\section{Socio-demographic information}

The mean age of respondents was 16.7 years. The age ranged from 13 to 22 years. Majority of the respondents $(82.7 \%)$ followed Hindu religion. More than half $(56.7 \%)$ of the respondents were residing in nuclear family (Table 1).

\section{Knowledge and view about ban on smoking in public places}

Of total 384 respondents who gave answer to the question, $79.9 \%$ said that there is ban on smoking in public place in Nepal. The most common source of information was television (72.3\%) followed by friend $(36.5 \%)$ and family members (33.9\%). Most of the respondents $(67.4 \%)$ said that they had frequently seen people smoking in public place. Similarly, $48.8 \%$ of total respondents had not heard or seen any penalty or punishment given to those people. Three quarters of respondents (74.2\%) believed that this type of ban could prevent cigarette smoking in adolescents to some or more extent (Table 2).

A total of 283 respondents $(74.1 \%)$ had the view that the current ban on smoking in public place was a very good thing. Of them 149 (52.7\%) gave the reason behind their view. The major reasons expressed by them are presented on the following themes:

- Protects from diseases: Fifty one responses reflected the view that this type of ban will prevent tobacco and cigarette smoking and hence protect people from diseases like cancer. They also believed that it saves peoples' life, helps in making people healthy and increase their longevity.

- Law is an effective strategy: Fifty responses reflected the view that strict law/legislative measure is an effective strategy to prevent smoking in public places. A common response was, "This type of law reduces the number of smokers by creating fear of penalty or punishment..........smokers will ultimately have to stop smoking in public places forcefully".

- Change the attitude of prospective smokers: Twenty three responses reflected the view that this type of governments' ban changes the attitude of adolescents towards smoking. One of the participants stated, "This type of law will discourage the non-smokers, ever smokers and current smokers to start or continue cigarette smoking".

- Prevent the health of other people in public places: Out of total 18 responses within this theme, most of the participants viewed that the ban would help prevent the health of other people in public places. Interestingly, some partici- 
Table 1: Socio-demographic information

\begin{tabular}{lll}
\hline Socio-demographic characteristics & Frequency & Percent \\
\hline Age $(\mathbf{n}=\mathbf{3 9 4})$ & 26 & 6.6 \\
13 to 15 years & 289 & 73.4 \\
16-17 years & 78 & 19.8 \\
18 to 19 years & 1 & 0.3 \\
More than or equal to 20 years & & \\
Sex (n=394) & 263 & 66.8 \\
Male & 131 & 33.2 \\
Female & & \\
Religion $(\mathbf{n}=\mathbf{3 9 4})$ & 343 & 87.1 \\
Hindu & 32 & 8.1 \\
Buddhist & 7 & 1.8 \\
Muslim & 7 & 1.8 \\
Christian & 5 & 1.3 \\
Others & & \\
Family Type $(\mathbf{n}=393)$ & 223 & 56.7 \\
Nuclear & 161 & 41 \\
Joint & 9 & 2.3 \\
Extended & &
\end{tabular}

Table 2: Knowledge and view about ban on smoking in public places

\begin{tabular}{|c|c|c|}
\hline Variables & Frequency & Percent \\
\hline \multicolumn{3}{|c|}{ Is there ban on smoking in public places in Nepal? $(n=384)$} \\
\hline Yes & 307 & 79.9 \\
\hline No & 77 & 20.05 \\
\hline \multicolumn{3}{|l|}{ Source of information $(n=307)$} \\
\hline Friend & 112 & 36.5 \\
\hline Television & 222 & 72.3 \\
\hline Family member & 104 & 33.9 \\
\hline Teacher & 66 & 21.5 \\
\hline Police & 49 & 16 \\
\hline Others (radio, poster, newspaper etc.) & 22 & 7.1 \\
\hline \multicolumn{3}{|c|}{ Seen people smoking in public places? $(n=387)$} \\
\hline Yes, frequently & 261 & 67.4 \\
\hline Yes, sometimes & 103 & 26.6 \\
\hline No & 23 & 5.9 \\
\hline \multicolumn{3}{|c|}{ Heard or saw penalty given to those smoking in public places? $(n=383)$} \\
\hline Yes, many times & 42 & 11 \\
\hline Yes, sometimes & 79 & 20.6 \\
\hline Yes, few times & 75 & 19.6 \\
\hline No & 187 & 48.8 \\
\hline \multicolumn{3}{|c|}{ Can such ban prevent smoking in adolescents? $(n=381)$} \\
\hline Yes, to much extent & 87 & 22.8 \\
\hline Yes, to some extent & 196 & 51.4 \\
\hline Does not prevent & 98 & 25.8 \\
\hline \multicolumn{3}{|l|}{ Is this type of ban good $(n=382)$} \\
\hline Very good & 283 & 74.1 \\
\hline Somewhat good & 68 & 17.8 \\
\hline Not good & 14 & 3.7 \\
\hline Not good at all & 17 & 4.5 \\
\hline
\end{tabular}


Dahal et al.

Table 3: Respondents view on ways of preventing smoking

\begin{tabular}{lll}
\hline What can be done to prevent smoking? $(\mathbf{n = 2 4 8})$ & Frequency & Percent \\
\hline Strict law & 81 & 32.6 \\
Raising awareness and counseling & 76 & 30.6 \\
Family support & 25 & 10.1 \\
Good friends circle & 9 & 3.6 \\
Ban on cigarette production and import & 55 & 22.1 \\
Ban or regulation on sale & 23 & 9.2 \\
Increase price & 8 & 3.2 \\
Ban advertisement & 21 & 8.4 \\
Employment opportunities & 15 & 6.04 \\
Other & 19 & 7.6
\end{tabular}

pants quoted the term 'second hand smoking' and viewed that it could be prevented by the current law.

- Other responses were, "this type of ban prevents environmental pollution"; "it helps to save money"; "it reduces crimes"; and "it helps to motivate self-control against smoking".

Similarly, out of 68 respondents $(17.8 \%)$ who said that the ban is somewhat good, some of the responses were; "the ban is good but smokers smoke anyway despite of strict law", "nothing is going to happen until effective measures for implementation are adopted", "it prevents air pollution", "it makes smokers cautious and careful while they think of smoking in public places".

Similarly, among the responses that were related to the view that the government's ban is not good, the major responses were; "By compelling people cannot be changed, activities should be done to make themselves aware of the effects of smoking", "To smoke or not to smoke in public places is peoples' own will", "People have the right to smoke".

\section{Ways of preventing smoking among adolescents and youths}

Two hundred and forty eight participants responded to the question asked to find out their ideas on possible ways of prevention of smoking among adolescents and youth. Among them, around $33 \%$ said, 'strict law should be made and implemented', followed by $30.6 \%$ who said 'awareness raising activity and counseling is required', $22.1 \%$ who said, 'cigarette production and import should be banned'. Similarly, need of family support (10.1\%), ban or regulated sale of cigarette (9.2\%), ban on advertisement (8.4\%) were other important responses. (Table 3)

\section{Discussion}

Knowledge and attitude are important predictors for effectiveness of legislation on smoking restriction (2). In this research, $79.9 \%$ respondents knew that there is ban on smoking in public place in Nepal with television being the most common source of this knowledge. Similarly, $74.1 \%$ of respondents had the view that the current ban on smoking in public place is very goodwhich is lower compared tothe findings from Global Youth Tobacco Survey (GYTS) report 2008 which suggested that $77.5 \%$ respondents from South East Asia Region supported ban on smoking in public places (17).

Literature suggests that developing countries are lagging behind in strict implementation of such smoking regulations (18). In this study also, as high as $68 \%$ respondents were mostly found to have seen the people smoking in public places. About $49 \%$ of all respondents had not seen or heard the offenders being penalized but many respondents viewed that effective implementation would require such penalty and other additional measures like awareness raising, regulation in cigarette import, production, advertisement and sale.

Global Youth Tobacco Survey on Smoke-Free Policies (SFPs) conducted among youth aged 13-15 years in 115 countries, primarily developing world found out that $77.3 \%$ of youths who participated in the study favored SFPs. The same study found that, knowledge on harmful effects of smoke was the strongest predictor of favoring SFPs (19). In the present study also, majority of respondents who believed that the current policy is good, gave the reason that cigarette smoking was harmful to health. They also viewed that this type of policy can discourage cigarette smoking among current and prospective smokers. On the other side, respondents who viewed the new regulation as bad reasoned that people had the right to smoke. They considered smoking as an individual business and this could not be changed by compelling people. These views reflect that for the effective implementation of the regulation, it also needs to win support from those who are more concerned about loss of personal freedom, excessive governmental power, use of compulsion, or the rights of smokers (20).

Different studies $(7,21)$ have also shown that support for smoking free policies lead to reduction of cigarette consumption. Studies have shown that the legislations to ban smoking in public places have led reduction in rates of second hand smoking, reduction in cardiac related hospital admissions and improvement in some health indicators (22). However, there is not much information on the effects of smoking regulation in Nepal which can be scope of further research.

\section{Conclusion}

Majority of the respondents had good knowledge and positive attitude towards governments' new smoking regulation. About half of the respondents said that they still saw people smoking in public places. This research suggests that effective implementation of smoking regulation requires awareness raising, regulation in cigarette import, production, advertisement and sale; and penalty to those who violate the law. 


\section{Limitations}

This research was carried out among the higher secondary level students of Kathmandu district and does not represent adolescent population in general. Only three colleges were included in the study and the findings of this study are based on self reported information from the participants.

\section{Competing interests}

The authors declare that they have no competing interests.

\section{Acknowledgements}

We are highly indebted to Dr. B.D. Chataut; principal, CIST college for his support and encouragement throughout the study. We would like to acknowledge all the colleges that gave permission for study. We acknowledge all the students who participated in the study. We would like to thank the data enumerators: Mr. Madhav KC and Mr. Saurav Chandra Acharya. The authors acknowledge University Grants Commission (UGC), Nepal for funding this study.

\section{Author E-mails}

${ }^{1}$ sushdahal@gmail.com,2sabeenamrj@gmail.com, ${ }^{3}$ rajkumarsubedi@gmail.com, ${ }^{4}$ juna.mhr@gmail.com

\section{References}

1. World Health Organization. Tobacco [Internet]. [cited 2014 Apr 21], Available from: http://www.who.int/mediacentre/factsheets/fs339/en/.

2. International Agency for Research on Cancer. Handbooks of cancer prevention: Tobacco control. 2009.

3. World Health Organization. WHO Global Report: Mortality Attributable to Tobacco. 2012.

4. Barnoya J, Glantz SA. Cardiovascular effects of secondhand smoke: nearly as large as smoking. Circulation. 2005;111:2684-98.

5. Eisner MD, Klein J, Hammond SK, Koren G, Lactao G, Iribarren C. Directly measured second hand smoke exposure and asthma health outcomes. Thorax. 2005;60:814-21

6. World Health Organization. About the WHO framework convention on tobacco control [Internet]. [cited 2014 Apr 21]; Available from: http://www.who.int/fctc/ about/en/.

7. Fichtenberg CM, Glantz SA. Effect of smoke $\neg$ free workplaces on smoking behaviour: systematic review. BMJ. 2002;325(188).

8. Wechsler H, Lee JE, Rigotti NA. Cigarette use by college students in smoke-free housing. Am J Prev Med. 2001;20:202-7.

9. Borowiec A, Lisowska I, Makowska M. What can public endorsement for a smoking ban policy mean? Preliminary findings from a qualitative study. Cent Eur J Public Health. 2013;21(3):128-133.

10. World Health Organization, Framework Convention on Tobacco Control. Nepal - New tobacco control bill approved [Internet]. [cited 2014 Apr 21]. Available from: http://www.who.int/fctc/implementation/news/nep/en/.

11. International Union against Tuberculosis and lung disease. $90 \%$ graphic health warnings now required on tobacco packs in Nepal [Internet]. [cited 2015 June 15]. Available from: http://www.theunion.org/news-centre/news/90-graphic-healthwarnings-now-required-on-tobacco-packs-in-nepal-2

12. Campaign for Tobacco free Kids. Tobacco Company Marketing to Kids [Internet]. [cited 2015 June 15]. Available from: http://www.tobaccofreekids.org/research/ factsheets/pdf/0008.pdf

13. Chadda RK, Sengupta SN. Tobacco use by Indian adolescents. Tob Induc Dis. 2002;1(2):111-119.

14. National Health Education Information and Communication Center. Nepal 2011 (Ages 13-15) Global Youth Tobacco Survey (GYTS) fact Sheet [Internet]. [cited 2014 Apr 21]. Available from: http://nheicc.gov.np/userfiles/file/tcp/NGYTSFS12.pdf.

15. Binu VS, Subba SH, Menezes RG, Kumar G, Ninan J, Rana MS, et al. Smoking among Nepali youth-prevalence and predictors. Asian Pac J Cancer Prev. 2010;11(1):221-6.

16. Schumann A, Ulrich J, Thyrian JR, Ulbricht S, Ulfert H, Christian M. Attitudes towards smoking policies and tobacco control measures in relation to smoking status and smoking behaviour. Eur J Public Health. 2006;16(5):513-519.

17. Center for Disease Control and Prevention. Global Youth Tobacco Surveillance, 2000-2007 [Internet]. [cited 2014 Apr 25]. Available from: http://www.cdc.gov/ $\mathrm{mmwr} / \mathrm{preview} / \mathrm{mmwrhtml} / \mathrm{ss} 5701 \mathrm{a} 1 . \mathrm{htm}$
18. Koh HK, Alpert HR, Judge CM, Caughey RW, Elqura LJ, Connolly GN, et al. Understanding worldwide youth attitudes towards smoke-free policies: an analysis of the Global Youth Tobacco Survey. Tob Control. 2011;20:219-225. 19. Borland R, Yong HH, Cummings KM, Hyland A, Anderson S, Fong GT. Determinants and consequences of smoke-free homes: findings from the International Tobacco Control (ITC) Four Country Survey. Tob Control. 2006;15(3):iii42-iii50.

20. Katz JE. Individual rights advocacy in tobacco control policies: an assessment and recommendation. Tob Control. 2005;14(2):ii31-ii37.

21. Gallus S, Zuccaro P, Colombo P, Apolone G, Pacifici R, Garattini S, et al. Effects of new smoking regulations in Italy. Ann Oncol.2006;17(2):346-7. 22. Callinan JE, Clarke A, Doherty K, Kelleher C. Legislative smoking bans for reducing secondhand smoke exposure, smoking prevalence and tobacco consumption. Cochrane Database Syst Rev. 2010;4. 